\title{
Inhibition of gas hydrates and corrosion behavior in gas field production facilities
}

\author{
Yunfeng Sun ${ }^{1,2, a}$, Mengmeng $\mathrm{Xu}^{1}$, Lei Zhang ${ }^{1}$ and Xue Dong ${ }^{3}$ \\ ${ }^{1}$ Key Laboratory for Enhanced Oil \& Gas Recovery of the Ministry of Education, Northeast Petroleum University, Daqing, \\ Heilongjiang, China \\ ${ }^{2}$ Gas Production Company, Daqing Oilfield Company Limited, Daqing, Heilongjiang, China \\ ${ }^{3}$ National Engineering Laboratory for Pipeline Safety, China University of Petroleum, Beijing, China
}

\begin{abstract}
Natural gas plays an essential role in satisfying the needs of energy in the world. Xushen gas field has been holding the balance of gas produced areas in China since exploitated in 2004. However, the exploitation effect in the field is challenged by the high-cold climate and amounts of $\mathrm{CO}_{2}$ in natural gas. A study of heat-tracing measures for preventing the formation of natural gas hydrates and selection of stainless steel pipelines and high-pressure facilities to inhibit $\mathrm{CO}_{2}$ corrosion behavior in the gas field production were performed recently. A case about the transportation technical limits of inhibiting the hydrates formation under different conditions was determined in this work. The results indicate that electrical heat tracing technology has better economic benefits than hot-water in the process of inhibiting the gas hydrates, the principal reason of corrosion are $\mathrm{CO}_{2}$ from the natural gas and $\mathrm{Cl}^{-}$in the produced water. When the differential pressure of $\mathrm{CO}_{2}$ is above $29 \mathrm{psi}$, it is promising that the steel should have exchanged to $316 \mathrm{~L}$ as the corrosion resistant material. This study is beneficial to comprehend corrosion mechanism and facilitate the development and application of innovative anticorrosive material in gas field production facilities.
\end{abstract}

Keywords: corrosion behavior, hydrate prevention, corrosion resistant material, gas field production.

\section{Introduction}

In recent years, the global energy sectors have undergone significant changes, and there have been a noticeable slowdown in requirement and an increasing competition in the traditional energy markets [1, 2]. According to a detailed analysis and forecasts of the development trend of the global energy sector, the world's consumption of primary energy would increase by only $40 \%$ (approximately $1.1 \%$ annually) from 2010 to 2040, which is threefold lower than the average annual GDP (gross domestic product) growth and significantly slower than the energy consumption growth observed over the past 30 years [3-5]. Undoubtedly, hydrocarbons would remain the basis of the world's energy over the period. At the same time, the structure of the world's energy consumption will become more diversified and balanced. Natural gas has advantages in combustion efficiency and lowing $\mathrm{CO}_{2}$ emissions in terms of sustainable energy. Its lower emission impact, price advantages and alternative ways of production making natural gas become

${ }^{a}$ Corresponding author: lyq04598848@ sina.com 
an important source of clean energy, and it will be the most popular type of fuel in decades to come in [6]. Under this background, efficient exploration and development of the condensate gas and other unconventional gas are urgent and promising. Also, the future development of natural gas will inevitably impact other fossil fuel industries. However, the development of natural gas will encounter challenges of technical bottlenecks and beneficial results similar to the development of oil, especially in the high-cold climate and poor reservoir property. Preventing the formation of hydrate and restraining the $\mathrm{CO}_{2}$ corrosion are beneficial to address the challenges.

In this paper, the specific treatment measures of preventing the formation of natural gas hydrates and restraining $\mathrm{CO}_{2}$ corrosion of Xushen gas field in Daqing (China) is presented respectively. Furthermore, the natural gas hydrates formation during transportation was discussed, and the gathering technical limits of inhibiting the hydrates formation under different conditions were also determined. The study will contribute to realizing the efficient development and utilization of clean energy.

\section{Exploration and development status quo of Xushen gas field}

The Xushen gas field, located in the north of Songliao Basin, is a potential giant gas area for China from the 1990s on. The gas field which belongs to typical dry gas field with low sulfur and high pressure has been developed and gone into production since 2004 . Its annual minimum temperature is $-36^{\circ} \mathrm{C}$, the depth of frozen ground can achieve to 2 meters because of it located in cold region. The shut-in pressure of most gas well range from $2900 \mathrm{psi}$ to $4350 \mathrm{psi}$, downhole flowing pressure is about $2900 \mathrm{psi}$, and the operation pressure of gathering pipeline after throttling range from 725 psi to 1015 psi. The sulfur content of the produced gas is lower than $10 \mathrm{mg} / \mathrm{L}$. But some blocks have high content of $\mathrm{CO}_{2}$ as higher than $20 \%$, the partial pressure of $\mathrm{CO}_{2}$ is about $145 \mathrm{psi}$, it cause serious corrosion to the equipments. The water production rate of several gas wells achieve to $30 \mathrm{~m} 3 / \mathrm{d}$. With continuous development of this gas field, poor property reservoir became the primary objective to produce gradually. This kind of reservoir has average porosity of $7.65 \%$ and mean permeability of $0.15 \times 10-3 \mu \mathrm{m} 2$, the lithological character of its matrix is compact, going against fluid driving. Facing with the condition that the low natural production capacity well are about $80 \%$ of the total, it is necessary to apply the fracturing technology to realize effective production of the commercial gas. Currently, the gas production of this field approach to nearly $15 \times 108 \mathrm{~m} 3 / \mathrm{a}$. The development practice of this field indicates that the investment of surface engineering is about $35.8 \%$ of the total, and the sum investment of surface gas production system, surface gas gathering pipeline and station are about $80 \%$ of the total surface engineering. It's necessary to put surface and subsurface integration into practice for reducing the investment and controlling the cost. And this is beneficial to realizing the efficient development of high pressure and low production gas field as well.

\section{Inhibition of gas hydrates}

The gas hydrates are considered as undesirable solids when they form in gas transportation and processing equipments. They can cause detrimental obstacles to the flow of gas, serious damages to instruments because of high pressure pipeline explosion [7].

The importance of the accurate hydrate formation prediction is evident because of its wide applications, such as determination of the limits for natural gas expansion during throttling in valves, chokes and restrictions, the amount of inhibitor to be injected and so on. Temperature and pressure is the key parameters which determine the formation of gas hydrates. The free water model which based on phase equilibrium is suit for these situations as follow, the phase of mixture hydrates which formed in pipeline is water-rich phase, gas phase and water-rich phase, hydrocarbon-water rich phase, gas phase with hydrocarbon-water rich phase [8]. Therefore, it is available to use PIPESYS (multiphase flow 
pipeline simulation software) with free water model for predicting the gas hydrates formation limits of gas gathering pipeline under different conditions.

Table1. Composition of natural gas.

\begin{tabular}{l|l}
\hline Composition & Mole fraction[\%] \\
\hline $\mathrm{CH}_{4}$ & 92.33 \\
$\mathrm{C}_{2} \mathrm{H}_{6}$ & 2.41 \\
$\mathrm{C}_{3} \mathrm{H}_{8}$ & 0.39 \\
$\mathrm{C}_{4} \mathrm{H}_{10}$ & 0.18 \\
$\mathrm{C}_{5} \mathrm{H}_{12}$ & 0.03 \\
$\mathrm{iC}_{6} \mathrm{H}_{14}$ & 0.02 \\
$\mathrm{CO}_{2}$ & 2.91 \\
$\mathrm{~N}_{2}$ & 1.73 \\
\hline
\end{tabular}

Taking one gas well in Xushen gas field as example, the gas production rate of this well is $50000 \mathrm{~m} 3 / \mathrm{d}$ and the water production rate is $10 \mathrm{~m} 3 / \mathrm{d}$. The composition of natural gas is summarized in Table 1 . The overall length of the surface gas gathering pipeline is $1289 \mathrm{~m}$, the temperature of well head is $24^{\circ} \mathrm{C}$, and the transportation pressure is $870 \mathrm{psi}$, the buried depth of pipeline is $2 \mathrm{~m}$, the thickness of silicate insulating layer is $40 \mathrm{~mm}$. So the formation limits relation between temperature and pressure of gas hydrates in this gas gathering pipeline is established.

Combining the hydraulic and thermal analysis to this pipeline, the formation temperature and location of gas hydrates can be predicted. As shown in Fig. 1, the hydraulic and thermal characteristics are intersecting with the relation; it reveals that the formation temperature limits of gas hydrates are $19.1^{\circ} \mathrm{C}$ under this condition. Furthermore, according to the thermal characteristic, the location of gas hydrates formation can be found which about $819 \mathrm{~m}$ away well head is. In other words, the rest of $470 \mathrm{~m}$ is the key areas of gas hydrates inhibition in this pipeline.

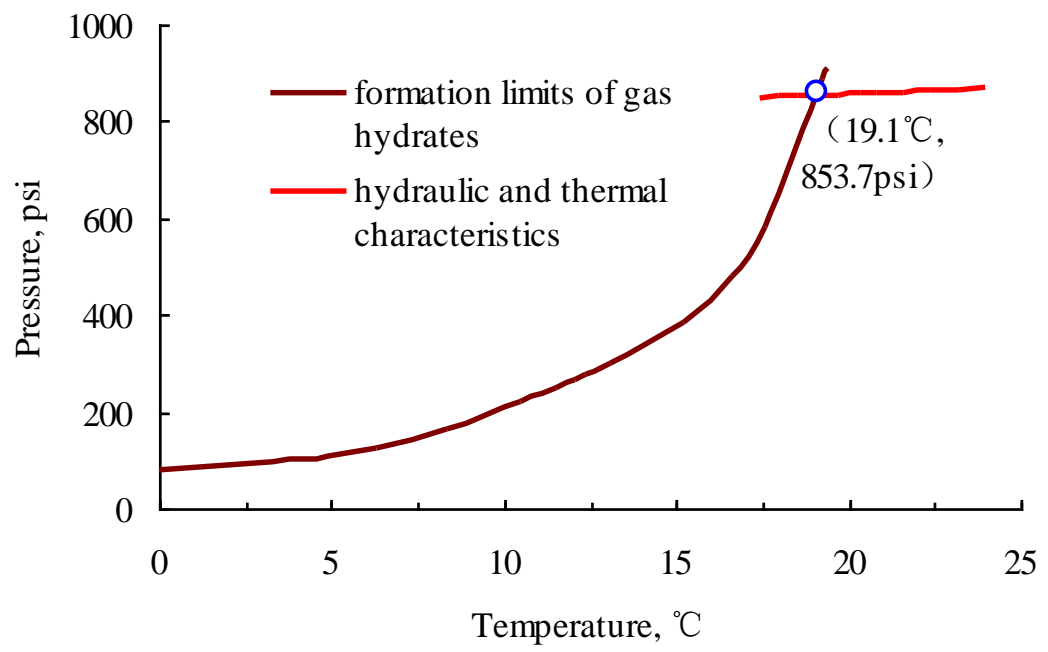

Figure 1. Determination of gas hydrates formation limits. 
The electrical heat-tracing technology and hot-water tracing technology are all feasible to inhibit hydrates formation as indicated above, but it is necessary to have a further comparison and selection for saving the operating cost and investment. It reveals that electrical heat tracing technology needs high investment, as 1.3 times higher as hot-water tracing technology. But its operation cost is lower, about 1/8 of the latter. In a word, electrical heat tracing technology has better economic benefits than hot-water in the process of inhibiting the gas hydrates.

\section{Inhibition of corrosion behavior}

Natural gas gathering system always encounter the challenge of corrosion. The results of the corrosion are $\mathrm{CO}_{2}$ from the gas and $\mathrm{Cl}$ - in the produced water, the safety and operation cost of field will be seriously affected. The corrosion of $\mathrm{CO}_{2}$ are influenced by temperature, differential pressure and material quality. But the solubility of $\mathrm{CO}_{2}$ which depends on pressure is the key to the corrosion. The primarily mechanism of corrosion is electrochemical which comes from the physicochemical reaction between $\mathrm{CO}_{2}$ and metallic matrix, and the factors cause palliation or promotion effect to the corrosion through their action on the formation of corrosion product [9].

Analyzing the corrosion condition of facilities from Xushen gas field, it reveals that corrosive pitting which would cause crippling is the main pattern. As shown in Figure 2, it has fatal destructiveness to metal, and the product is soft and easy to strip. The black corrosion product on surface is $\mathrm{FeCO}_{3}$, as shown in Figure 3, elemental composition includes $\mathrm{Fe}, \mathrm{O}, \mathrm{Ca}, \mathrm{Cl}, \mathrm{Na}$ and so on, and the content of $\mathrm{Fe}, \mathrm{O}$ and $\mathrm{Ca}$ is much higher.

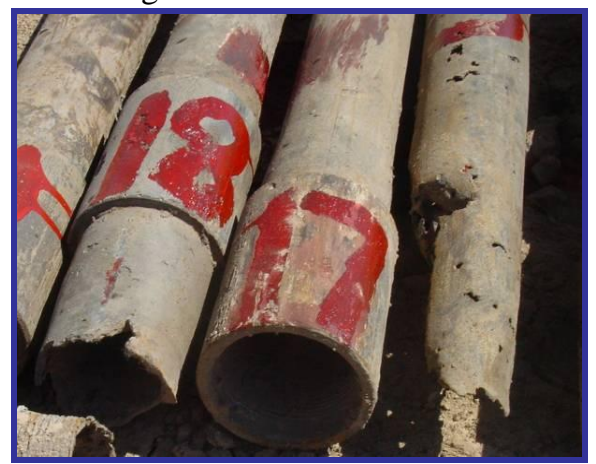

Casing tube after corrosion

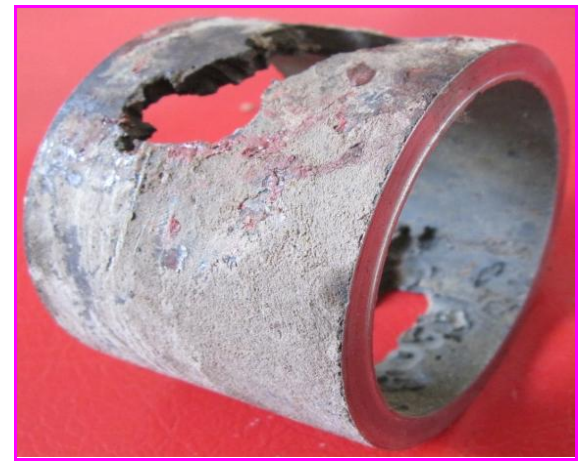

Oil tube after corrosion

Figure 2. Corrosion condition of facilities.

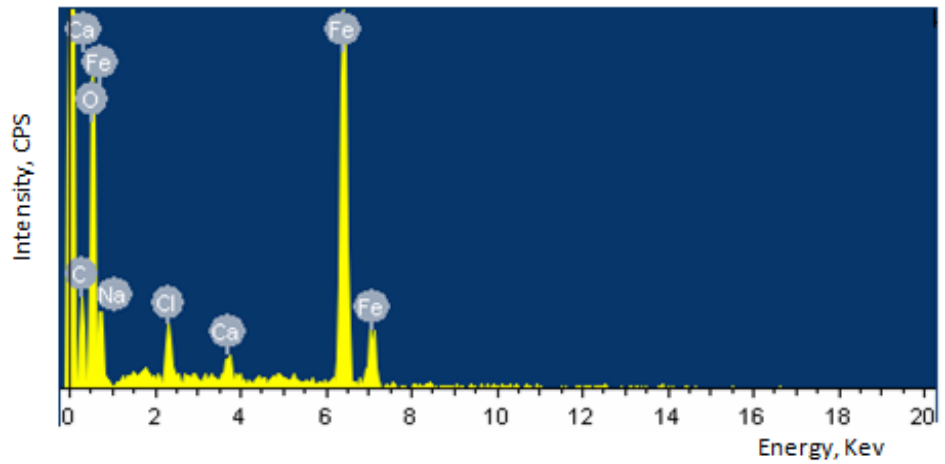

Figure 3. Energy spectrum of corrosion product. 
Several targeted field practice are carried out for corrosion preventing. In high pressure and normal temperature area $\left(2900 \sim 3625 \mathrm{psi},<30^{\circ} \mathrm{C}\right)$ which the pipeline from well head to station, the differential pressure of $\mathrm{CO}_{2}$ is 2.9 to $29 \mathrm{psi}, 20$ carbon steel is still selected for the steel of pipeline, but the wall thickness is intensified by 1 2mm, and the anti-corrosive agent is injected into. During this process, the inhibition efficiency of corrosion is above $80 \%$, and the corrosion rate is controlled below $0.02 \mathrm{~mm} / \mathrm{a}$. When the differential pressure of $\mathrm{CO}_{2}$ is above 29psi, the steel have exchanged to 316L corrosion resistant material. As shown in Fig. 4, the corrosion is effectively relieved. In high pressure and high temperature area $\left(2900 \sim 3625 \mathrm{psi}, 50^{\circ} \mathrm{C}\right)$ which the pipeline from heating furnace to outlet throttle valve, except for the corrosion rate of $\mathrm{CO}_{2}$ reaches to maximum approximately, the corrosion result from $\mathrm{Cl}$ - can not be ignored at this moment. So, comprehensive and effective methods should be taken into consideration in this situation.

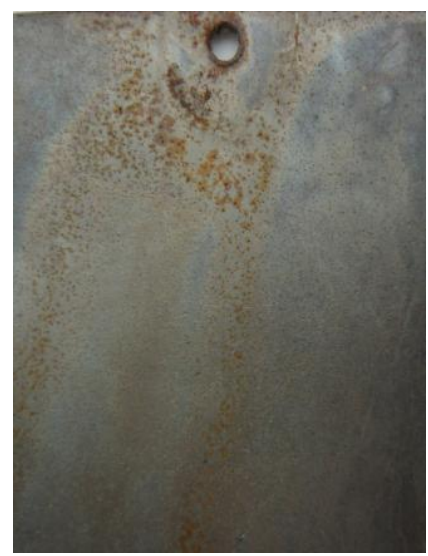

Corrosion condition of $20 \#$ steel

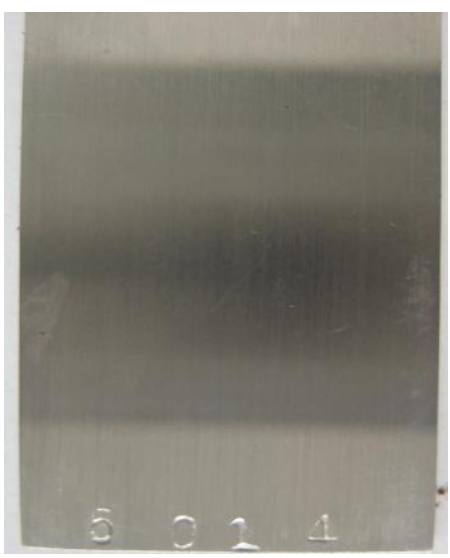

Corrosion condition of $316 \mathrm{~L}$ steel

Figure 4. Corrosion conditions of test blocks in gas gathering system.

\section{Conclusions}

Natural gas will be applied extensively in the energy consumption structure, and the efficient development for gas reservoir would be promoted. It is important to prevent gas hydrates from forming in gas transportation and production facilities. The evaluation indicates that electrical heat tracing technology has better economic benefits than hot-water in the process of inhibiting the gas hydrates. Gas gathering system always encounters corrosion, and the principal reason of corrosion is $\mathrm{CO}_{2}$ from the natural gas and $\mathrm{Cl}$ - in the produced water. Corresponding to different corrosion degree, it is available to slow down the corrosion and prolong the service life of facilities by replacing materials and injecting anti-corrosive agent.

\section{Acknowledgements}

This work was financially supported by the State Key Program of National Natural Science Foundation of China (Grant No. 51534004), and the Science and Technology Innovation Foundation of CNPC (Grant No. 2014D-5006-0607) is gratefully acknowledged. 


\section{References}

1. M. E. Bildirici, T. Bakirtas, The relationship among oil, natural gas and coal consumption and economic growth in BRICTS (Brazil, Russian, India, China, Turkey and South Africa) countries, Energy, 65 (2014).

2. H. Bloch, S. Rafiq, R. Salim, Coal consumption, $\mathrm{CO}_{2}$ emission and economic growth in China: empirical evidence and policy responses, Energy Economics, 34, 518-528 (2012).

3. Y. H. Zheng, D. K., Luo, Industrial structure and oil consumption growth path of China: Empirical evidence, Energy. 57, 336-343 (2013).

4. Z.H. Wang, R.S. Pang, X.P. Le, Peng, Survey on injection-production status and optimized surface process of ASP flooding in industrial pilot area, Journal of Petroleum Science and Engineering, 111, 178-183 (2013).

5. H. Zhong, Z. Wang, E. Cao, The study on increase low permeability reservoir adsorption ability with nano-polymerisation emulsion, International Journal of Oil, Gas and Coal Technology, 6, 507-516 (2013).

6. H. Gurgul, L. Lach, The role of coal consumption in the economic growth of the Polish economy in transition, Energy Policy, 39, 2088-2099 (2011).

7. W.Q. Li, J. Gong, X.F. Lü, A study of hydrate plug formation in a subsea natural gas pipeline using a novel high-pressure flow loop, Petroleum Science, 10, 97-105 (2013).

8. Y. Liu, J.X. Li, Z.H. Wang, S.Z. Wang, The role of surface and subsurface integration in the development of a high-pressure and low-production gas field, Environmental Earth Science, 73, 5891-5904 (2015).

9. Z.H. Wang, X.L. Zhuge, An environmentally-friendly method for removing polymer plugging in well boreholes, Petroleum Science and Technology, 32, 2763-2769 (2014). 